\title{
Kinetics of Radical Polymerization with Primary Radical Termination
}

\author{
Katsukiyo ITO, Makoto ŌMI,* and Toshikuni ITO* \\ Government Industrial Research Institute, Nagoya, \\ Kita-ku, Nagoya 462, Japan.
}

(Received June 18, 1981)

\begin{abstract}
The polymerization initiated by 1-phenylethyl radical (PER) and diphenylmethyl radical (DPMR) at $50^{\circ} \mathrm{C}$ was studied to clarify the causes of deviation in the polymerization rate $R_{\mathrm{p}}$ from $R_{\mathrm{p}} \propto[\mathrm{C}]^{1 / 2}[\mathrm{M}]$ ([C], initiator concentration and $[\mathrm{M}]$, monomer concentration). In the polymerization of styrene initiated by PER, the term defined as primary radical termination (PRT) can not be used to explain the deviation, because of $k_{\mathrm{i}} \simeq k_{\mathrm{p}}\left(k_{\mathrm{i}}\right.$, rate constant of addition of primary radical to monomer and $k_{\mathrm{p}}$, propagation rate constant). Thus, the deviation should be explained by the dependence of polymer-polymer termination (PPT) on chain length. In the polymerization initiated by DPMR, both the PRT term and the dependence of PPT on chain length are necessary to explain the deviation, because of $k_{\mathrm{i}} \ll k_{\mathrm{p}}$, where $k_{\mathrm{i}}=37 \mathrm{dm}^{3} \mathrm{~mol}^{-1} \mathrm{~s}^{-1}$ (styrene) and 2.5 (methyl methacrylate).
\end{abstract}

KEY WORDS Phenylethyl Radical / Diphenylmethyl Radical / Primary Radical Termination / Polymer-Polymer Termination / Styrene / Methyl Methacrylate /

In the polymerization of styrene, methyl methacrylate (MMA), and methacrylonitrile (MA) initiated by $2,2^{\prime}$-azobisisobutyronitrile (AIBN), the rate constant of addition of a primary radical to a monomer has been estiamted to be $k_{\mathrm{i}}=$ $k_{\mathrm{pMA}}\left(k_{\mathrm{p} 12} / k_{\mathrm{p} 11}\right)$ where $k_{\mathrm{pMA}}$ and $k_{\mathrm{p} 12} / k_{\mathrm{p} 11}$ are designated as the rate constant of the homopolymerization of MA and $1 / r_{1}$ in the copolymerization of MA $\left(\mathrm{M}_{1}\right)-\mathrm{M}_{2}$ system, respectively. ${ }^{1,2,11}$ The $k_{\mathrm{i}}$ value obtained is nearly equal to the propagation rate constant of the respective homopolymerization (that is, $k_{\mathrm{i}} \simeq k_{\mathrm{p}}$ ). If this is true, an approximation as $\bar{k}_{\mathrm{ti}} / k_{\mathrm{i}} k_{\mathrm{p}} \simeq \bar{k}_{\mathrm{t}, 1} / k_{\mathrm{p}}{ }^{2}$ can be used. That is, $\bar{k}_{\mathrm{t}, 1}$ may be treated as a part of ${\overline{k_{\mathrm{t}}}}^{2,3}$ Therefore, the deviation of polymerization rate from eq 1 can not be explained on the basis of the primary radical termination rate, but rather by the dependence of polymer-polymer termination rate on the chain length. ${ }^{1-3}$

$$
R_{\mathrm{p}} \propto[\mathrm{C}]^{1 / 2}[\mathrm{M}]
$$

If $k_{\mathrm{i}} \ll k_{\mathrm{p}}$ is satisfied, the effect of primary radical

* On leave from Aichi Institute of Technology, Yagusa, Toyota, Japan. termination is important to explain the deviation from eq 1. This has been typically illustrated in terms of a kinetic treatment of the polymerization of vinyl acetate (VA) initiated by AIBN. ${ }^{4}$

In the present paper, the polymerization of styrene and MMA in the presence of 1-azobisphenylethane (APE) ${ }^{5}$ azobisdiphenylmethane (ADM) ${ }^{6}$ and 1-phenylethylazodiphenylmethane $(\mathrm{PADM})^{7}$ was studied to reconfirm the above explanation.<smiles>CC(=NC(C)c1ccccc1)c1ccccc1</smiles>

(APE)<smiles>c1ccc(N=NC(c2ccccc2)c2ccccc2)cc1</smiles>

(ADM)<smiles>CC(N=C(c1ccccc1)c1ccccc1)c1ccccc1</smiles> 
The primary radicals formed by the decomposition of these azo initiators are the 1-phenylethyl radical: $\mathrm{CH}_{3} \mathrm{CHC}_{6} \mathrm{H}_{5}$ (PER) and the diphenylmethyl radical: $\mathrm{C}_{6} \mathrm{H}_{5} \dot{\mathrm{C}}_{\mathrm{HC}} \mathrm{H}_{5}$ (DPMR). The structure of PER resembles that of the end radical of polymer in the polymerization of styrene, and therefore the prediction that $k_{\mathrm{i}} \simeq k_{\mathrm{p}}$ is satisfied. On the other hand, DPMR is more stable than PER, in view of resonance theory. ${ }^{6}$ Thus, it is expected that the rate constant of addition to the monomer is considerably smaller than the propagation rate constant. That is, the condition that $k_{\mathrm{i}} \ll k_{\mathrm{p}}$ is satisfied. The data obtained are treated by the kinetic equations reported before. ${ }^{2,4}$

\section{EXPERIMENTAL}

APE, ADM, and PADM were prepared by methods described in earlier articles. ${ }^{5-7}$ Commercial styrene and MMA were also purified by a method described earlier. ${ }^{4}$ The polymerization solutions containing the above azo initiators were prepared at about $10^{-3} \mathrm{mmHg}$ by the freeze-thaw technique. The polymerization was conducted at $50.0 \pm 0.05^{\circ} \mathrm{C}$. The conversions were estimated by liquid chromatography. The ultimate conversion was below $8 \%$. The values of $\bar{n}$ were estimated from $M_{\mathrm{n}}$ obtained by gel permeation chromatography (GPC). Here, $M_{\mathrm{n}}$ of polystyrene was estimated by using a GPC calibration curve made by the relationship between the molecular weight $M$ of the polystyrene standard and elution volume. To estimated $M_{\mathrm{n}}$ of poly(MMA), this curve was modified by in accordance with the fact that $[\eta] \mathrm{M}$ was independent of the kind of polymer at given elution volume. ${ }^{8,9}$

\section{RESULTS AND DISCUSSION}

The kinetic data obtained are shown in Tables I through IV. Clearly, the deviation of $R_{\mathrm{p}}$ from eq 1 is seen in the data obtained in any polymerization system. That is, $\left(R_{\mathrm{p}} /[\mathrm{C}]^{1 / 2}[\mathrm{M}]\right)$ increases with a decrease in [C]. In order to explain similar deviations, the effect of primary radical termination was considered, ${ }^{10}$ without examining the dependence of the polymer-polymer termination rate on the chain length. On the other hand, some theoretical treatments indicate that the polymer-polymer termination depends on chain length, where the chain length is a function of [C] and [M]..$^{3,11-13}$ To avoid this confusion, an equation not involving the polymer-polymer termination was derived. ${ }^{2}$ Considering the transfer to initiator, this equation is experessed as,

$$
\frac{f k_{\mathrm{d}}[\mathrm{C}]}{R_{\mathrm{p}}\left(1 / \bar{n}-C_{\mathrm{trM}}-C_{\mathrm{tr}}[\mathrm{C}][\mathrm{M}]\right)}=1+\frac{\bar{k}_{\mathrm{ti}}}{k_{\mathrm{i}} k_{\mathrm{p}}} \cdot \frac{R_{\mathrm{p}}}{[\mathrm{M}]^{2}}
$$

If the primary radical termination rate is negligibly small (that is, inequality 3 is adoptable), eq 2 reduces to eq 4 .

$$
\begin{gathered}
1 \gg \frac{\bar{k}_{\mathrm{ti}} R_{\mathrm{p}}}{k_{\mathrm{i}} k_{\mathrm{p}}[\mathrm{M}]^{2}} \\
\frac{[\mathrm{M}]}{[\mathrm{C}]}\left(\frac{1}{\bar{n}}-C_{\mathrm{trM}}\right)=C_{\mathrm{trI}}+f k_{\mathrm{d}} \cdot \frac{[\mathrm{M}]}{R_{\mathrm{p}}}
\end{gathered}
$$

Setting up $C_{\mathrm{trM}}=4.0 \times 10^{-5},{ }^{14}$ eq 4 is fitted to the data obtained in the polymerization initiated by PER (Table I). A good linear relationship based on eq 4 obtained (Figure 1). This means that the inequality 3 can be used. Accordingly, the primary

\begin{tabular}{|c|c|c|c|}
\hline$[C]$ & $10^{5} R_{\mathrm{p}}$ & & $10^{6} R_{\mathrm{p}} /[\mathrm{C}]^{1 / 2}[\mathrm{M}]$ \\
\hline $\mathrm{mol} \mathrm{dm}^{-3}$ & $\mathrm{~mol} \mathrm{dm}{ }^{-3} \mathrm{~s}^{-1}$ & & $\mathrm{dm}^{3 / 2} \mathrm{~mol}^{-1 / 2} \mathrm{~s}^{-1}$ \\
\hline 0.200 & 1.901 & 2310 & 5.34 \\
\hline 0.100 & 1.484 & 3710 & 5.75 \\
\hline 0.050 & 1.120 & 5011 & 6.07 \\
\hline 0.025 & 0.861 & 7413 & 6.55 \\
\hline 0.0125 & 0.617 & 9485 & 6.60 \\
\hline
\end{tabular}

Table I. Bulk polymerization of styrene initiated by $\mathrm{APE}$ at $50.0^{\circ} \mathrm{C}$

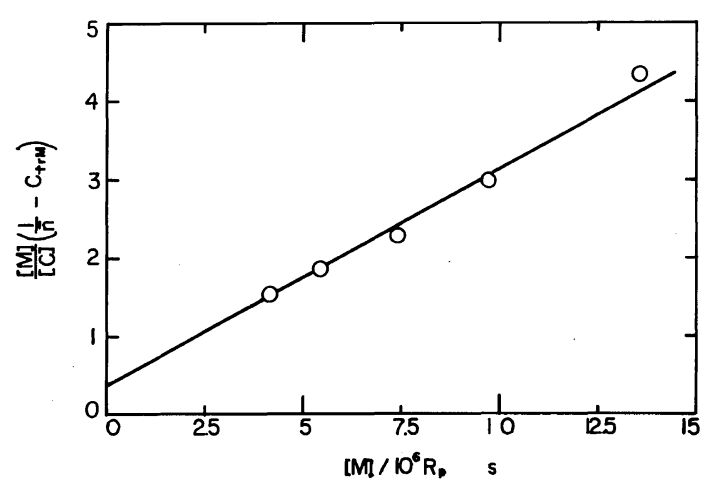

Figure 1. Application of eq 4 to the data in the polymerization of styrene initiated by APE (Table I). 
Polymerization with Primary Radical Termination

Table II. Polymerization of styrene initiated by ADM at $50.0^{\circ} \mathrm{C}$

\begin{tabular}{|c|c|c|c|c|}
\hline$[C]$ & {$[\mathrm{M}]$} & $10^{5} R_{\mathrm{p}}$ & & $10^{6} R_{\mathrm{p}} /[\mathrm{C}]^{1 / 2}[\mathrm{M}]$ \\
\hline $\mathrm{mol} \mathrm{dm} \mathrm{m}^{-3}$ & $\mathrm{~mol} \mathrm{dm}-3$ & $\mathrm{~mol} \mathrm{dm} \mathrm{m}^{-3} \mathrm{~s}^{-1}$ & & $\mathrm{dm}^{3 / 2} \mathrm{~mol}^{-1 / 2} \mathrm{~s}^{-1}$ \\
\hline $0.1033^{\mathrm{a}}$ & 2.00 & $1.1,0.9$ & & $1.7,1.4$ \\
\hline $0.1033^{a}$ & 4.01 & 3.44 & & 2.67 \\
\hline $0.1033^{\mathrm{a}}$ & 8.04 & 14.9 & 107 & 5.76 \\
\hline 0.0258 & 8.28 & 10.68 & 238 & 8.03 \\
\hline 0.00646 & 8.36 & 7.16 & 542 & 10.66 \\
\hline 0.00161 & 8.36 & 4.49 & 1178 & 13.39 \\
\hline 0.000404 & 8.36 & 2.56 & 2435 & 15.24 \\
\hline 0.000101 & 8.36 & 1.401 & 4980 & 16.67 \\
\hline
\end{tabular}

a Benzene was used as solvent.

Table III. Polymerization of MMA initiated by ADM at $50.0^{\circ} \mathrm{C}$

\begin{tabular}{|c|c|c|c|c|}
\hline$[\mathrm{C}]$ & {$[\mathrm{M}]$} & $10^{5} R_{\mathrm{p}}$ & & $10^{5} R_{\mathrm{p}} /[\mathrm{C}]^{1 / 2}[\mathrm{M}]$ \\
\hline $\mathrm{mol} \mathrm{dm}^{-3}$ & $\mathrm{~mol} \mathrm{dm}^{-3}$ & $\mathrm{~mol} \mathrm{dm} \mathrm{m}^{-3} \mathrm{~s}^{-1}$ & & $\mathrm{dm}^{3 / 2} \mathrm{~mol}^{-1 / 2} \mathrm{~s}^{-1}$ \\
\hline $0.1040^{\mathrm{a}}$ & 1.09 & $1.9,1.5$ & & $5.3,4.2$ \\
\hline $0.1040^{\mathrm{a}}$ & 2.18 & 5.16 & & 7.17 \\
\hline $0.1040^{\mathrm{a}}$ & 4.36 & 22.5 & & 15.63 \\
\hline 0.1040 & 8.72 & 68.8 & 412 & 23.9 \\
\hline 0.0260 & 8.99 & 52.7 & 843 & 36.3 \\
\hline 0.00650 & 9.04 & 33.1 & 1725 & 45.4 \\
\hline 0.00163 & 9.04 & 20.6 & 3239 & 55.7 \\
\hline 0.000460 & 9.04 & 12.02 & 6403 & 66.0 \\
\hline 0.0001202 & 9.04 & 6.88 & 14500 & 75.4 \\
\hline
\end{tabular}

a Benzene was used as solvent.

radical termination term $\left(\bar{k}_{\mathrm{t}} / k_{\mathrm{i}} k_{\mathrm{p}}\right)$ is unnecessary. $f$ and $C_{\mathrm{trI}}$ were estimated from the slope and intercept of the line and are shown in Table V. Previously, the deviation of $R_{\mathrm{p}}$ from eq 1 was explained by considering only primary radical termination, without examining the data on $\bar{k}_{\mathrm{t}}$ as a function of $\bar{n}^{15} \mathrm{In}$ view of eq 4 , this explanation is incorrect. Therefore, the deviation of $R_{\mathrm{p}}$ from eq 1 should be explained by the dependence of polymer-polymer termination rate, where $\bar{k}_{\mathrm{ti}} / k_{\mathrm{i}} k_{\mathrm{p}} \simeq \overline{\mathrm{k}}_{\mathrm{t}, 1} / k_{\mathrm{p}}^{2}$ because of $k_{\mathrm{i}} \simeq k_{\mathrm{p}},{ }^{1-3}$ as stated in the Introduction.

On the other hand, eq 4 cannot be used for treating the data obtained in the polymerization initiated by DPMR (Tables II and III), since a negative value is obtained for $C_{\mathrm{tr}}$. This means that primary radical termination is important in this case. To apply eq 2 to the data shown in Tables II and III, the value of $\bar{k}_{\mathrm{ti}} / k_{\mathrm{i}} k_{\mathrm{p}}$ must be determined. To estimate this value, eq 5 must be used. ${ }^{4}$

$$
R_{\mathrm{p}}=\frac{k_{\mathrm{i}} k_{\mathrm{p}}}{\bar{k}_{\mathrm{ti}}}[\mathrm{M}]^{2}
$$

In the present case, eq 5 is applicable to the data obtained for styrene at $[\mathrm{M}] \leq 8.04 \mathrm{~mol} \mathrm{dm}^{-3}$ and $[C]=0.1033$ and for MMA at $[\mathrm{M}] \leq 4.36 \mathrm{~mol} \mathrm{dm}^{-3}$ and $[\mathrm{C}]=0.104$, as seen in Figure $2 . \bar{k}_{\mathrm{ti}} / k_{\mathrm{i}} k_{\mathrm{p}}$ was found to be $4.5 \times 10^{5} \mathrm{~mol} \mathrm{~s} \mathrm{dm}^{-3}$ (styrene) and $8.5 \times 10^{4}$ (MMA). To treat the data in Tables II and III, eq 2 is rewritren as:

$$
\begin{aligned}
& \frac{[\mathrm{M}]}{[\mathrm{C}]}\left(\frac{1}{\bar{n}}-C_{\mathrm{trM}}\right) \\
& \quad=C_{\mathrm{trI}}+f k_{\mathrm{d}}\left[\frac{[\mathrm{M}]}{R_{\mathrm{p}}\left(1+\bar{k}_{\mathrm{ti}} R_{\mathrm{p}} / k_{\mathrm{i}} p_{\mathrm{p}}[\mathrm{M}]^{2}\right)}\right]
\end{aligned}
$$

Applicability of eq 6 to the data obtained in the polymerization of styrene can been seen in Figure 3, since $C_{\text {trl }}$ is a positive value. The values obtained are 


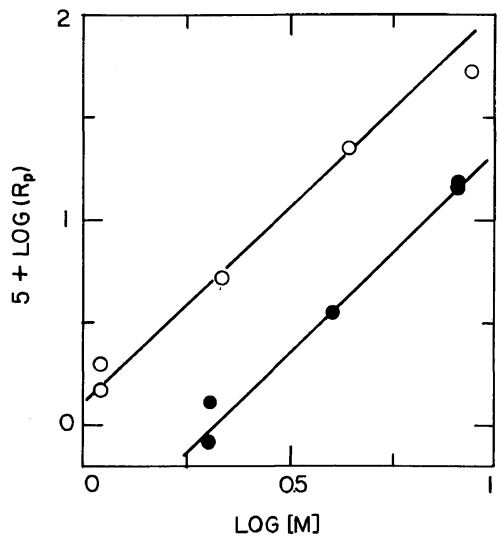

Figure 2. Application of eq 5 to the data in the polymerization of styrene $\left(O,[\mathrm{ADM}]=0.1033 \mathrm{~mol} \mathrm{dm}^{-3}\right.$ in Table II) and MMA (O, 0.104 in Table III).

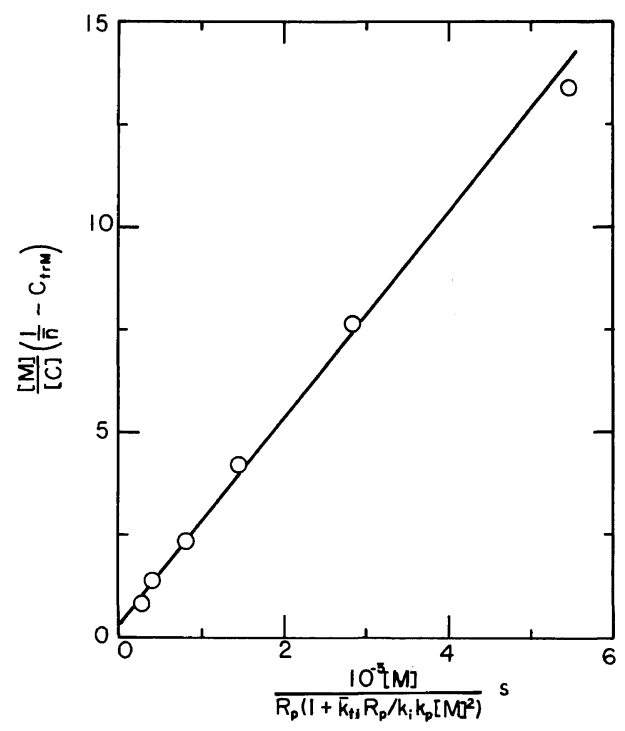

Figure 3. Application of eq 6 to the data in the polymerization of styrene initiated by ADM (Table II), where $\bar{k}_{\mathrm{ti}} / k_{\mathrm{i}} k_{\mathrm{p}}=4.5 \times 10^{5} \mathrm{~mol} \mathrm{~s} \mathrm{dm}^{-3}$.

shown in Table V. In order to apply eq 6 to the data obtained in the polymerization of MMA, $C_{\mathrm{trM}}$ is set as $1.08 \times 10^{-5} .16$ This applicability is shown in Figure 4. The values obtained for $C_{\text {trl }}$ and $f$ are shown in Table V.

To apply eq 2 to the data obtained in the polymerization initiated by both PER and DPMR (Table IV), it is rewritten as:

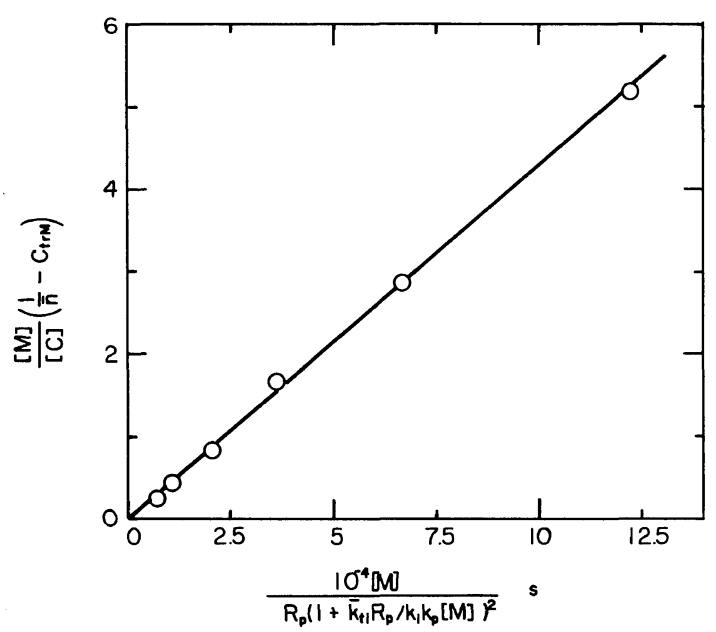

Figure 4. Application of eq 6 to the data in the polymerization of MMA initiated by ADM (Table III), where $\bar{k}_{\mathrm{ti}} / k_{\mathrm{i}} k_{\mathrm{p}}=8.5 \times 10^{4} \mathrm{~mol} \mathrm{~s} \mathrm{dm}^{-3}$.

Table IV. Bulk polymerization of styrene initiated by PADM at $50.0^{\circ} \mathrm{C}$

\begin{tabular}{lcccc}
\hline \multicolumn{1}{c}{$[\mathrm{C}]$} & & $10^{5} R_{\mathrm{p}}$ & & $10^{5} R_{\mathrm{p}} /[\mathrm{C}]^{1 / 2}[\mathrm{M}]$ \\
\cline { 1 - 1 } \cline { 5 - 5 } $\mathrm{mol} \mathrm{dm}^{-3}$ & & $\mathrm{~mol} \mathrm{dm}^{-3} \mathrm{~s}^{-1}$ & & $\mathrm{dm}^{3 / 2} \mathrm{~mol}^{-1 / 2} \mathrm{~s}^{-1}$ \\
\hline 0.0560 & & 9.56 & 389 & 4.60 \\
0.0140 & & 4.98 & 918 & 5.06 \\
0.00350 & & 2.70 & 1965 & 5.46 \\
0.000875 & 1.429 & 3670 & 5.79 \\
0.000219 & 0.760 & 8036 & 6.14 \\
\hline
\end{tabular}

$$
\begin{aligned}
& 2 R_{\mathrm{p}}\left(\frac{1}{\bar{n}}-C_{\mathrm{trM}}-C_{\mathrm{tr} 1} \cdot \frac{[\mathrm{C}]}{[\mathrm{M}]}\right) \\
& \quad=\frac{f k_{\mathrm{d}}[\mathrm{C}]}{1+\bar{k}_{\mathrm{ti} 1} R_{\mathrm{p}} / k_{\mathrm{i} 1} k_{\mathrm{p}}[\mathrm{M}]^{2}}+\frac{f k_{\mathrm{d}}[\mathrm{C}]}{1+\bar{k}_{\mathrm{ti} 2} R_{\mathrm{p}} / k_{\mathrm{i} 2}[\mathrm{M}]^{2}}
\end{aligned}
$$

Because $1 \gg k_{\mathrm{ti} 1} R_{\mathrm{p}} / k_{\mathrm{i} 1} k_{\mathrm{p}}[\mathrm{M}]^{2}$ as shown before, eq 7 should be reduced to:

$$
\begin{aligned}
& \frac{[\mathrm{M}]}{[\mathrm{C}]}\left(\frac{1}{\bar{n}}-C_{\mathrm{trM}}\right) \\
& \quad=C_{\mathrm{tr}}+f k_{\mathrm{d}} \cdot \frac{[\mathrm{M}]}{2 R_{\mathrm{p}}}\left(1+\frac{1}{1+\bar{k}_{\mathrm{t} 2} R_{\mathrm{p}} / k_{\mathrm{i} 2} k_{\mathrm{p}}[\mathrm{M}]^{2}}\right)
\end{aligned}
$$




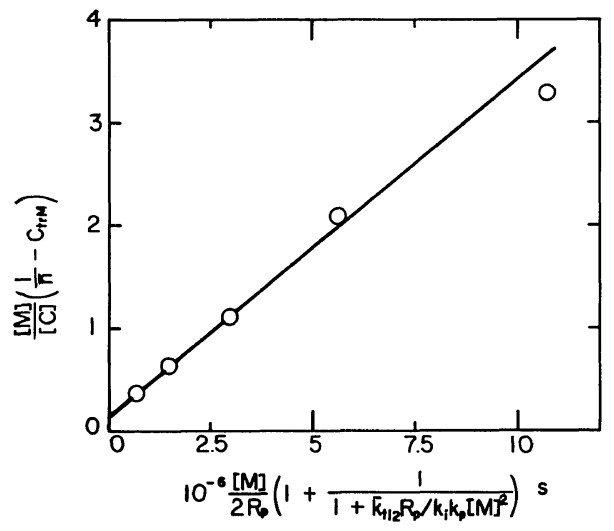

Figure 5. Application of eq 8 to the data in the polymerization of styrene initiated by PADM (Table IV), where $\bar{k}_{\mathrm{t} 2} / k_{\mathrm{i} 2} k_{\mathrm{p}}=4.5 \times 10^{5} \mathrm{~mol} \mathrm{~s} \mathrm{dm}^{-3}$.

The applicability of eq 8 is shown in Figure 5. The values obtained for $C_{\mathrm{trI}}$ and $f$ are shown in Table V, and $C_{\text {trPADM }}$ are somewhat smaller than $C_{\text {trADM }}$. In view of the above, it may be said that the kinetic treatment based on eq 2 has been experimentally verified.

The primary radical termination rate is probably diffusion-controlled. This means that $\bar{k}_{\mathrm{tAIBN}} \simeq$ $\bar{k}_{\text {tiADM}} \cdot{ }^{1-3}$

Thus, to estimate the value of $k_{\mathrm{i}}$, the following equation may be used,

$$
k_{\mathrm{iADM}} \simeq \frac{k_{\mathrm{iAIBN}}\left(\bar{k}_{\mathrm{ti}} / k_{\mathrm{i}} k_{\mathrm{p}}\right)_{\text {AIBN }}}{\left(\bar{k}_{\mathrm{ti}} / k_{\mathrm{i}} k_{\mathrm{p}}\right)_{\mathrm{ADM}}}
$$

The values used here are: $\left(\bar{k}_{\mathrm{ti}} / k_{\mathrm{i}} k_{\mathrm{p}}\right)_{\mathrm{AIBN}}=27900 \mathrm{~mol}$ $\mathrm{s} \mathrm{dm}{ }^{-3}, k_{\text {iAIBN }}=595 \mathrm{dm}^{3} \mathrm{~mol}^{-1} \mathrm{~s}^{-1}$ for styrene at $50^{\circ} \mathrm{C}$ and $\left(\bar{k}_{\mathrm{ti}} / k_{\mathrm{i}} k_{\mathrm{p}}\right)_{\mathrm{AIBN}}=1420, k_{\mathrm{i}}=149$ for MMA at $50^{\circ} \mathrm{C}^{17,18}$ The calculated values are shown in Table $\mathrm{V}$, where the prediction that $k_{\mathrm{i}} \ll k_{\mathrm{p}}$ is satisfied. In the above discussion, if the steric effect for $\bar{k}_{\mathrm{tiADM}}$ is larger than that for $\bar{k}_{\mathrm{tiAlBN}}$, (meaning that $\left.\bar{k}_{\mathrm{tiADM}}<\bar{k}_{\mathrm{tiAIBN}}\right), k_{\mathrm{i}} \ll k_{\mathrm{p}}$ should be satisfied more completely.

\section{CONCLUSION}

In the polymerization of styrene and MMA initiated by DPMR initiated by the dimethylcyanomethyl radical (DCMR) ${ }^{4} k_{\mathrm{i}} \ll k_{\mathrm{p}}$ is satisfied, and therefore the primary radical termination term is important in explaining the deviation of $R_{\mathrm{p}}$ from eq 1 . On the other hand, in the polymerization of styrene and MMA initiated by PER and DCMR, ${ }^{1}$ the radical termination term is unnecessary and the deviation of $R_{\mathrm{p}}$ from eq 1 is explained only by the dependence of the polymer-polymer termination rate on the chain length, because $k_{\mathrm{i}} \leq k_{\mathrm{p}}$. In the polymerization of styrene, $k_{\text {iAIBN }}=595 \mathrm{dm}^{3} \mathrm{~mol}^{-1}$ $\mathrm{s}^{-1}$ is considerably larger than $k_{\mathrm{p}}=123 . \bar{k}_{\mathrm{ti}} / k_{\mathrm{i}} k_{\mathrm{p}}$ at $k_{\mathrm{i}}>k_{\mathrm{p}}$ is smaller than that at $k_{\mathrm{i}}=k_{\mathrm{p}}$. Thus, when $k_{\mathrm{i}}>k_{\mathrm{p}}$, primary radical termination is not important in explaining the deviation of $R_{\mathrm{p}}$ from eq 1 .

\section{NOMENCLATURE}

$R_{\mathrm{p}} \quad, \quad$ polymerization rate

$\bar{n} \quad$, number average degree of polymerization

[C] , initiator concentration

[M] , monomer concentration

$f \quad$, the fraction of primary radical escaping from the solvent cage

Table $\mathbf{V}$. Values obtained in polymerization initiated by azo initiators at $50.0^{\circ} \mathrm{C}$

\begin{tabular}{|c|c|c|c|c|c|c|}
\hline \multirow{2}{*}{ Monomer } & \multirow{2}{*}{ Initiator } & $10^{8} k_{\mathrm{d}}^{\mathrm{a}}$ & \multirow{2}{*}{$f$} & \multirow{2}{*}{$C_{\mathrm{trI}}$} & $k_{\mathrm{p}}^{\mathrm{b}}$ & $k_{\mathrm{i}}$ \\
\hline & & $\mathrm{s}^{-1}$ & & & \multicolumn{2}{|c|}{$\mathrm{dm}^{3} \mathrm{~mol}^{-1} \mathrm{~s}^{-1}$} \\
\hline Styrene & APE & 5.75 & 0.41 & 0.0075 & 123 & 123 \\
\hline Styrene & PADM & 668 & 0.46 & $0.2 \pm 0.05$ & 123 & 123,37 \\
\hline Styrene & ADM & 6070 & 0.48 & $0.3 \pm 0.1$ & 123 & 37 \\
\hline MMA & ADM & 6070 & 0.58 & 0 & 285 & 2.5 \\
\hline VA & AIBN & & & & 2640 & $7.92^{\mathrm{c}}$ \\
\hline
\end{tabular}

a Calculated by the respective Arrhenius equations in ref $5-7$.

b From ref 19.

c From ref 18. 
$k_{\mathrm{d}} \quad, \quad$ initiator decomposition rate constant

$k_{\mathrm{p}} \quad, \quad$ propagation rate constant

$k_{\mathrm{i}} \quad$, rate constant of addition of primary radical to monomer $\left(k_{\mathrm{i} 1}\right.$ is for PER, $k_{\mathrm{i} 2}$ for DPME)

$\bar{k}_{\mathrm{ti}} \quad$, primary radical termination rate consatant $\left(\bar{k}_{\mathrm{t} 11}\right.$ is for PER, $k_{\mathrm{ti} 2}$ for DPME)

$\bar{k}_{\mathrm{t}, 1} \quad$, rate constant of termination between polymer radical and radical with one monomer unit

$C_{\mathrm{trM}} \quad$, the relative transfer constant of polymer radical to monomer

$C_{\text {trl }} \quad$, the relative transfer constant of polymer radical to initiator

$[\eta] \quad$, intrinsic viscosity

$M_{\mathrm{n}} \quad$, number-average molecular weight

\section{REFERENCES}

1. K. Ito, J. Polym. Sci., Polym. Chem. Ed., 15, 1764 (1977).

2. K. Ito, Macromolecules, 13, 193 (1980).

3. K. Ito, Polym. J., 11, 795 (1979).

4. K. Ito, J. Polym. Sci., Polym. Chem. Ed., 15, 2037 (1977).

5. S. G. Cohen, S. G. Groszos, and D. B. Sparrow, J.
Am. Chem. Soc., 72, 3947 (1950).

6. S. G. Cohen and C. H. Wang, J. Am. Chem. Soc., 77, 2457 (1955).

7. K. Ito and Y. Ōnishi, Polym. J., to be submitted.

8. Z. Grubisic, R. Rempp, and H. Benoit, J. Polym. Sci., B5, 753 (1967).

9. H. K. Mahabadi and K. F. O'Driscoll, J. Appl. Polym. Sci., 21, 1283 (1977).

10. C. H. Bamford, A. D. Jenkins, and R. Johnstone, Trans. Faraday Soc., 55, 1451 (1959), and papers cited in ref 2 .

11. K. Ito, J. Polym. Sci., Polym. Chem. Ed., 10, 3159 (1972).

12. K. Horie, I. Mita, and H. Kambe, Polym. J., 4, 341 (1973).

13. H. K. Mahabadi and K. F. O'Driscoll, J. Polym. Sci., Polym. Chem. Ed., 15, 283 (1977).

14. G. V. Schulz, G. Henrici, and S. Olivé, Z. Elecktrochem., 60, 296 (1956).

15. O. F. Olaj, Makromol. Chem., 114, 1 (1968).

16. N. S. Stickler and G. Meyerhoff, Makromol. Chem., 179, 2729 (1978).

17. H. K. Mahabadi and K. F. O'Driscoll, Makromol. Chem., 178, 2629 (1977).

18. K. Ito, J. Polym. Sci., A-1, 10, 148 (1972).

19. M. S. Matheson, E. E. Auer, E. B. Bevilacqua, and E. J. Hart, J. Am. Chem. Soc., 71, 497, 2610 (1949); ibid., 73, 1701 (1951). 